\title{
ACIDENTE DO TRABALHO E PREVIDENCIA SOCIAL
}

\author{
JULIO ASSUMPÇÃO MALHADAS
}

(Professor Titular de Direito do Trabalho na Faculdade de Direito da Universidade Católica do Paraná, Docente Livre na Faculdade de Direito da Universidade Federal do Paraná, Juiz do Trabalho)

\author{
SUMÁRIO \\ 1 - Previdência Social \\ 11 - Seguro contra acidente do trabalho \\ III - Acidente do Trabalho e Previdência Social \\ IV - Conclusão.
}

PREVIDENCIA SOCIAL

O que é Previdência Social?

O nome é composto por aglutinação. Para melhor estudo, faça-se a decomposição: "previdência" e "social".

Previdência, diz o Caldas Aulete, é substantivo feminino, proveniente de "previdente", com as acepções de "vista ou conhecimento do futuro. / Conjetura. / Precaução, cautela, previsão. / Presciência", previdente, por sua vez, consta como adjetivo, vindo do latim "proevidens", com as acepções de "que prevê. / Precavido, acautelado. / (e por extensão) Prudente, sensato". Enquanto assim consta do Caldas Aulete, no Dicionário Escolar Latino-Português de Ernestc Faria (edição do Ministério da Educação e Cultura), temos "providens. -entis" como particípio presente de "provideo" que, por seu turno, é verbo transitivo com "I - sentido próprio: 1) Ver antecipadamente. prever, pressentir", como foi usado por Horacio e Cicero, e "Il - Daí: 2) Prover a, olhar por, fazer provisão", sentido em que o usaram Júlio César e Cícero.

Temos, pois, que previdência é visão do futuro e, ao mesmo tempo, é cuidado por referência a êsse futuro; é conjetura ("presunção, 
¡uízo formado sôbre aparência, fundado em indícios, em probabilidades; hipótese, suposição" - segundo o mesmo Caldas Aulete) a respeito do que poderá ocorrer, e é tomada de cautelas, de medidas que evitem o que se previu que irá acontecer, ou minorem seus resultados.

É assim. que previdente se chama ao homem que amealha recursos, que economiza para garantir sua subsistência e a dos seus no momento em que não lhe seja possível trabalhar, ou porque a idade o impeça, ou porque acidente, enfermidade ou qualquer outra causa não lhe permita trabalhar.

Social, o que é?

Diz o mesmo dicionarista, que é adjetivo, com a acepção de "que diz respeito à sociedade", provindo do latim "socialis", e o dicionário latino-português dá para "socialis" o sentido próprio de "relativo aos aliados" e o sentido derivado "feito para a sociedade".

Porém, para o caso da Previdência Social, o adjetivo social significa tratar-se de prevenir prejuízos que afetam à coletividade, mas também que, em razão do alcance de tais prejuízos, o Estado aí intervém, seja contribuindo (direta ou indiretamente) com recursos, seja oferecendo garantias, seja outorgando facilidades para sua existência, seja tornando-a obrigatória.

Assim, a previdência, que é considerada uma virtude pessoal, passa a ser um dever social, impôsto pelo Estado em razão do interêsse da sociedade.

Esta Previdência Social, que se diferencia da simples previdência ùnicamente pelo fato da intervenção do Estado e pela conseqüente obrigatoriedade, visa, então, a ter o trabalhador a coberto dos prejuízos que podem decorrer da impossibilidade de ganhar, da impossibilidade de ter salários com que atender a suas necessidades e às de sua família, impossibilidade que pode decorrer de riscos normais da existência, sejam os de caráter biológico, como os relativos a modificações do Estado de saúde (e, por conseqüencia, da capacidade de trabalhar) ou mesmo à da vida, sejam os de caráter econômico-social como os relativos ao desemprêgo. Entre os fatos causadores dos primeiros riscos, estão os acidentes do trabalho.

A Previdência Social se exerce através do seguro social. Seguro, porque, a exemplo do que ocorre no seguro privado, o risco é coberto por alguém que recebe uma importância predeterminada e em troca se responsabiliza pelas consequências previstas; social, porque obrigatório e porque nêle interfere o Estado. 
Tal seguro cobre os riscos já referidos, devendo cobrir também o de acidentes do trabalho. Todavia, não tem sido êste seguro (o contra acidentes do trabalho) aceito por todos como um seguro social, porque, dizem, é um seguro que atende aos interêsses do empresário, porque o segurador o substitue em suas responsabilidades, e não aos interêsses do empregado e da sociedade.

Isto será visto a seguir.

II

\section{SEGURO CONTRA ACIDENTE DO TRABALHO}

O que é seguro contra acidente do trabalho?

Inicialmente, recorde-se que o empresário responde pelo acidente do trabalho, embora nem sempre haja sido assim, e embora no futuro não deva ser assim.

Houve tempo em que o acidente do trabalho era simples infortúnio, a que estava exposto o trabalhador e pelo qual ninguém era responsável.

Cuidou-se depois, de beneficiar ao trabalhador, responsabilizando ao empresário, a fim de que êste custeasse a recuperação ou ao menos o tratamento do acidentado e o indenizasse pelo dano sofrido.

Para fundamentar essa responsabilidade do empresário, adotou-se inicialmente a teoria da culpa. Desde que o trabalhador provasse a culpa do empresário no fato de que decorrera seu infortúnio, ao empresário caberia a responsabilidade. Mas isto demandava um processo caro e difícil para fazer a prova, do que resultava, quase sempre, a irresponsabilidade do empregador.

Passou-se a apontar como fonte da responsabilidade o próprio contrato de trabalho. Ao contratar o trabalhador, o empresário estaria assumindo, entre outras, a obrigação de lhe dar condições de trabalho de absoluta segurança, e a ocorrência do acidente implicaria em demonstrar que as providências necessárias não haviam sido tomadas. Mas, se a responsabilidade era contratual, também por contrato poderia ser excluída e realmente o era, através de cláusulas contratuais explícitas, inutilizando-se assim o esfôrço em favor do trabalhador.

Em nova fase, a responsabilidade passou a decorrer não de culpa ou de contrato, mas do simples fato de que sendo o empresário o promotor da atividade do trabalhador dêle deviam ser todos os riscos, inclusive os relativos a acidentes do trabalho. Não se indaga, pois, da existência de culpa, nem da vontade manifestada no contratc: 
- empresário é sempre o responsável pelo acidente e arca com suas conseqüências (salvo se provar a existência de qualquer das cláusulas excludentes de responsabilidade previstas na lei).

A tendência atual, é a de se considerar o acidente do trabalho uma responsabilidade social, uma decorrência da vida da sociedade e do desenvolvimento industrial e comercial e, portanto, ônus de tôda a sociedade, e não apenas do empresário cujo trabalhador se acidentou.

Recordadas estas noções, voltemos ao tema.

Se a responsabilidade é do empresário, a êste cabe, ocorrido o acidente, atender ao tratamento do trabalhador, à sua recuperação, à sua recolocação em condições de prover à própria subsistência $e$ à de sua família, ou the cabe atender diretamente a essas subsis. tências, se impossível aquela devolução à plena atividade.

Não raramente, porém, nesse momento de acorrer em socorro do trabalhador, está o empresário impossibilitado de o fazer, por falta de recursos. E então? O trabalhador fica desamparado.

Para evitar tal situação, fazia-se necessário encontrar uma forma de garantia da efetivação daquela responsabilidade, e essa forma foi o seguro, como poderia ter sido a obrigatoriedade de uma fiançą ou de um depósito bancário, ou outra.

E, pois, o seguro contra acidentes do trabalho, na fase atual, uma simples garantia de que o trabalhador não ficará desamparado. não ficará sem tratamento, não ficará sem recuperação, ou sem inde nização, por falta de recursos do empresário. É uma forma de previ. dência, embora paga por terceiro e não por aquêle que é o seu beneficiário.

O segurador é, pois, terceiro interveniente na relação entre empresário e trabalhador, terceiro que entra em substituição ao empresário, para cumprir o que a êste caberia cumprir no caso de acidente do trabalho.

III

\section{ACIDENTE DO TRABALHO E PREVICENCIA SOCIAL}

Previdência Social, foi visto, é a provisão (visão antecipada) dos fatos que podem prejudicar a atividade do trabalhador no sentido de se manter e de manter a família, e a adoção de medidas, de cautelas, que the permitam, e a sua família, sobreviver. É social, porque $c$ Estado participa de sua efetivação, tornando-a obrigatória e para ela contribuindo em razão do interêsse social. 
A previdência social se exercita através do seguro social obrigatório e controlado pelo Estado (que para êle deve contribuir), assegurando ao trabalhador, na ocorrência dos fatos que the impossibilitem manter-se (ou a sua família), os recursos para essa manutenção.

O seguro contra acidente do trabalho é, como também já foi visto, uma garantia de que o trabalhador acidentado e sua família não ficarão sem recursos para se manter, é, como ficou escrito, uma forma de previdência.

Não há dúvida, não é possível contestar, que o seguro contra acidente do trabalho é, assim, do maior interêsse social.

Os que dizem ser êste seguro simplesmente do interêsse do empresário, não consideram o fato de que a segurança do trabaIhador, quanto a seu tratamento, a sua readaptação (quando necessária) ou a sua indenização, é do maior interêsse social.

Assim sendo, desde que o seguro é uma forma de previdência, e uma vez que o de acidentes do trabalho é de grande interêsse social, por isso obrigatório, não há negar que seguro contra acidente do trabalho é uma das formas de realização da Previdência Social.

Se iá assim é, quando se considera de responsabilidade do empresário as consequências do acidente do trabalho, porque êle $́$ o empreendedor e o beneficiário da atividade do trabalhador, com mais razão assim há de ser ao se considerar tal acidente como uma responsabilidade social, porque a atividade da emprêsa visa à utilidade social e porque o bem estar do trabalhador, parcela da socie dade, há de ser preocupação fundamental desta.

O que se tem discutido, é se o seguro contra acidentes do trabalho há de ser monopólio do Estado, através dos órgãos da previdência social, ou se o Estado deve-se abster de nêle operar ou, em correntes ecléticas, se há de ser campo de competição entre o Estado e o particular. tatal.

Em Deveali encontramos a razão para que haja o monopólio es-

"... evitando que el resarcimiento de los accidentes se convierta en materia de especulación mercantil".

Por que evitar que se especule com o seguro contra acidentes do trabalho? Porque na especulação, visando ao maior lucro, nem sempre (ou quase nunca) se tem presente o interêsse do trabalhador infortunado ou o da sociedade. Interessa o maior volume de lucro, e para alcançá-lo necessário se torna maior número de empresários pagando prêmios (e na busca dêsse maior número, prêmios devem 
diminuir ou as "facilidades" ou "concessões" ao empresário aumentar). Interessa o maior volume de lucro, e para alcançá-lo necessário se torna reduzir o custo, as despesas com o atendimento aos acidentados (e na busca dessa redução, surgem as dificuldades aos atendimentos, surgem as amputações e extirpações de membros ou de órgãos, porque de menor custo do que sua recuperação ou seu tratamento, não importando que o homem fique inutilizado ou com capacidade reduzida e passe a ser um "pêso" para a sociedade; surgem as demoras, as procrastinações, as "chicanas" nos processos de pagamento de indenizações, com o fito de não as pagar ou pagá-las em valor inferior ao devido; desaparece o interêsse pela recuperação ou pela readaptação do trabalhador).

Qual a finalidade da Previdência Social no que diz respeito aos acidentes do trabalho?

Em parte, ela se confunde com a da Segurança do Trabalho, ou podemos dizer que esta funciona como instrumento daquela. Prevenir, quando se fala em acidente do trabalho, é, primeiramente, precìpuamente, antever as conseqüências danosas à vida, à integridade física, à saúde, à capacidade do trabalhador (não só como trabalhador, mas como pessoa humana), que podem advir daquele trabalho, do ambiente em que seja executado, das condições em que se realize, do método de trabalho, do instrumental utilizado. Antevistas as conseqüências danosas, prevenir é afastá-las, tanto quanto possível, e à Segurança do Trabalho (a Segurança pròpriamente dita, ou a Higiene do Trabalho, que com a Segurança se estuda e é também uma forma de segurança) é que se recorre para obter os meios de evitar tais conseqüências.

Temos até aquí, Previdência Social e Segurança do Trabalho, unidas, se interpenetrando, no afã de evitar a ocorrência do acidente (ou da doença, que como acidente se considera).

Mas, por fatalidade, apesar de tôda prevenção, ou por falha da parte do trabalhador, ou do empresário, ou de terceiro, o acidente ocorre. Previdência, então, passa a significar ter havido cuidado de estabelecer meios de reparação do mal, que afastem, não mais o evento, que êste já ocorreu, mas as más conseqüências dêste. Prevenir, então, com vistas a êste segundo aspecto, é dispor de forma a que, ocorrido o acidente, o trabalhador e sua família não sofram as más consequiências, ou as sofram no gráu mínimo possível.

No que consistirá esta prevenção, esta reparação? Em dar ao trabalhador todo o atendimento, médico, cirúrgico, ortopédico, odontológico, psicológico, escolar, pecuniário, ou de qualquer outra 
natureza, que seja necessário ou seja útil, no sentido de afastar ou reduzir a dor e as outras formas de sofrimento; no sentido de the preservar a vida, a integridade física e a capacidade (não só a de trabalho) que tinha antes do acidente; no de substituir órgãos ou membros que não possam mais ser restaurados em seu funcionamento de modo satisfatório (e nesta era dos transplantes, já há possibilidade de não se ficar restrito às substituições por peças artificiais); no de recuperá-lo, sempre que possível, para que continue a fazer tudo quanto fazia antes do acidente, ou readaptá-lo (física, psicológica e profissionalmente) para novas atividades, quando a recuperação seja impossível; no sentido de lhe garantir a manutenção (no mesmo padrão de vida a que estava habituado) própria e a de sua família até o momento em que esteja novamente em condições de assegurá-la por seus próprios recursos, ou até ao fim da vida se não mais lhe fôr possível assegurá-la por sí mesmo; no sentido de assegurar a seus dependentes a manutenção, no mesmo padrão anterior ao acidente, de sua vida, se do acidente resultar ao trabaIhador (direta ou indiretamente, imediata ou mediàtamente) a morte.

Note-se que não se fala em soluções alternativas, e sim em soluções que não se excluem umas às outras, salvo nos casos em que as situações previstas sejam incompatíveis entre sí. Assim, a preservação da vida não afasta a recuperação ou a readaptação e não exclui a manutenção durante êsse processamento, como as tentativas de manutenção da vida do acidentado não excluem a garantia da subsistência dos dependentes, no caso de morte posterior do acidentado, por não haver dado resultado a tentativa de salvar-lhe a vida.

É de se perguntar se com a previdência particular, do próprio trabalhador, será possível pensar-se em tão ampla assistência. Quanto custaria ao trabalhador um seguro privado que the pudesse garantir tudo isto? Estaria êle em condições de pagá-lo? E a seguradora não teria a tentação de aumentar seu lucro, pela redução da assistência?

Também é de se perguntar se qualquer emprêsa estará em condições de, através de uma apólice de seguro garantir tôda essa assistência a seus trabalhadores. Quanto lhe custaria tal apólice? E a seguradora não teria interêsse em aumentar seus ganhos?

No entanto, se a reparação não tiver essa amplitude, se não se der tudo quanto foi alinhado, o trabalhador estará sendo prejudicado, o homem estará sofrendo e perdendo, sua família também, e os reflexos na sociedade não deixarão de se fazer sentir, com maior 
ou menor intensidade, com maior ou menor carga de emotividade, com maior ou com menor prejuízo para a própria sociedade.

Não há, verdadeiramente, seguro contra acidente do trabalho, se o homem é desfalcado de membro ou de órgão que poderia ser tratado e recuperado, se é atirado à inatividade quando poderia ser readaptado em outra função, se é transformado em "parasita" quando poderia ser ainda um cidadão prestante. As indenizações não substituem o homem, não pagam seu sofrimento, não o fazem mais feliz.

O seguro social para atender aos acidentes do trabalho, traz a vantagem de, pelo maior número de contribuintes, pela ausência de fito de lucro, poder custar menos ao empresário e ainda assim, pro. porcionar maiores e melhores benefícios ao acidentado e seus depen. dentes, salientando-se, que só através do seguro social será possível pensar-se em recuperação e em readaptação.

É certo que há opositores à integração do acidente do trabalho à Previdência Social, opositores de boa-fé e opositores de má-fé (interessados, por qualquer razão, em que se mantenham os seguros contra acidentes do trabalho no campo de ação das compannias particulares).

Seus argumentos, porém, não podem mudar o que já foi exposto e que corresponde à realidade e à orientação do bom senso (tanto assim, que em $70 \%$ dos países em que há êsse seguro, se adotou o regime do seguro estatal).

Alegam, por exemplo, que a Previdência Social já não atende satisfatòriamente a suas atribuições atuais, havendo constantes $e$ reiteradas reclamações dos trabalhadores, enquanto que não há reclamações contra a atuação das companhias seguradoras. Isto levaria à conclusão da inconveniência de retirar o seguro das companhias que estariam atendendo bem aos interessados, para entregá-lo a quem já não estaria atendendo satisfatòriamente aos encargos que tem, mas levaria também, lògicamente, à conclusão de que também o regime de aposentadorias e pensões deveria competir àquelas companhias (o que não lhes interessa e, por essa razão, não foi lembrado). Realmente, o atendimento dos órgãos da Previdência Social vem deixando algo a desejar, mas isto pode e deve ser corrigido, eliminando as reclamações que, na verdade, têm havido, e a correção poderá ser feita com o nôvo contingente de recursos que o próprio seguro contra acidentes do trabalho lhe carreia. Mas, não é certo que não tenha havido reclamações contra o atendimento pelas companhias seguradoras, e se mais reclamações não tem havido, não é por falta de razão para 
reclamar: quem não sabe que as seguradoras não se preocupam com recuperação, e menos ainda com readaptação de acidentados? que elas se limitam à assistência médico-hospitalar, ou ambulatorial, pelo prazo mais curto possível e às indenizações pagas no prazo mais longo que possam? que procuram todos os meios possíveis para contestar os pedidos de indenização e para levar os processos correspondentes ao máximo possível de duração e ao mínimo de pagamento? que em 1966 havia 16.000 processos de indenização por acidentes do trabalho em andamento na Guanabara e, 40.000 em São Paulo? que os ambulatórios das seguradoras procuram da, alta aos acidentados, a qualquer custo, mesmo sem que estejam em condições para tanto (o representante dos trabalhadores rurais na comissão paritária que estudou a reformulação da Previdência Social, defendendo as seguradoras particulares, citou que os ambulatórios da Previdência Social levavam vinte dias para dar alta ao acidentado, enquanto os das companhias o faziam em dez dias)?

Argumentam, com o benefício que a correspondência entre as emprêsas traria à melhoria dos serviços, como se ao empresário, que é quem escolhe a seguradora, fôsse interessar (por exceção, interessá a alguns) a qualidade da assistência a ser dada ao trabalhador (ao empresário interessa, de regra, apenas cumprir a obrigação legal de realizar o seguro, e procura fazê-lo com o menor dispêndio possível). Mas não explicam porque as seguradoras não fazem questão dessa concorrência, não se opõem ao monopólio (que elas mesmas constituiram a favor da Previdência Social, ao se desinteressarem de tais seguros) dos chamados "maus seguros", os que oferecem mais ou maiores riscos, como no caso dos trabalhadores portuários, da estiva e outros (como bem observa Rezende Puech em um de seus artigcs a respeito em "O Estado de São Paulo", jornal que defende o seguro privado, embora Puech defenda o seguro social). Também não explicam, porque sòmente dezenove, das cento e noventa e uma emprêsas de seguros, operavam em seguro contra acidentes do trabatho, sem que as demais se preocupassem com a falta de maior concorrência...

Parece que o argumento que realmente leva à defesa dos segu. ros privados contra acidentes do trabalho, é êste usado em editorial de "O Estado de São Paulo":

"Esste monopólio... também constituiria uma grave ameaça às companhias seguradoras nacionais. Com efeito, os prê. mios para êste risco representam $36 \%$ da arrecadação total das companhias privadas e para as companhias que trabá lham neste ramo 56\%. Com a instituição do monopólio, 
estas companhias sofreriam um verdadeiro colapso finan ceiro. Seriam obrigadas a realizar imediatamente boa parte dos seus ativos, o que teria por efeito uma baixa considerável nos mercados dos títulos no momento preciso em que o govêrno está querendo fortalecer o mercado finan ceiro.

A maior parte das empresas seguradoras que trabalham neste ramo utilizam os lucros provenientes do seguro de acidentes de trabalho para cobrir o deficit de outro ram:o e notadamente do seguro de automóveis. Não poderão sustentar tais encargos e iremos assistir a uma verdadeira desnacionalização desta atividade, enquanto atualmente são ùnicamente companhias nacionais que fazem seguro de acidente de trabalho".

Todavia, êste é o argumento que menos aceitável se apresenta e é um dos ex-diretores do mesmo jornal, o saudoso e ilustre jurista e político Plínio Barreto (apud Rezende Puech, no artigo já citado), quem o repele:

"Não se compreende, realmente, que a dor e a miséria alheia, possam ser objeto de mercadoria. Êste seguro, social por sua própria natureza, deve ser social por sua forma de exploração. A aludida transferência proporcionaria, desde logo, às instituições de previdência, imensos recursos finan. ceiros que seriam aplicados na melhoria da assistência médica a ser prestada pelas mesmas instituições a seus segurados e respectivos dependentes" (parecer, como rela. tor, aprovado pela Comissão de Investigação Econômica e Social da Câmara dos Deputados em 1946).

Manter o seguro contra acidentes do trabalho na esfera privada, para possibilitar a subsistência das companhias, para cobrir o deficit deixado pelo seguro de automóveis, parece não ter cabimento, e seria argumento que Plínio Barreto não aceitaria. Por outro lado, como, de onde, vêm êsses lucros, num ramo de seguros que deve dar prejuízo? Como é possível haver lucros no seguro contra aciden.. tes do trabalho, num país recordista em acidentes do trabalho? SE sòmente no Paraná, cuja industrialização é ainda incipiente, se aci dentou em 1966 um trabalhador de cada três que estavam em atividade, de onde pode vir o lucro das seguradoras? não será apenas resultado de assistência não prestada ou prestada deficien. temente?

Na realidade, desde 1942 foi afirmado (Plano Beveridge) estar - seguro privado contra acidentes do trabalho superado pelo seguro 
social, e a legislação britânica, adotando referido plano, o integrou no seguro-invalidez.

\section{IV \\ CONCLUSÃO}

Como não é possível ao trabalhador fazer sua própria previdência para a ocorrência de acidente do trabalho, à Previdência Social cabe ampará-lo.

Como não é possível ao empresário oferecer através do seguro privado todo o amparo, tôda a assistência, tôdas as condições para que possa haver reparação do acidente, para que o acidentado e seus dependentes não sofram, ou sofram ao mínimo, as conseqüências do evento, à Previdência Social caberá fazê-lo.

Não só ao empresário, mas a tôda a sociedade, cabe a respon. sabilidade pelo acidente do trabalho, porque não só o empresário é beneficiário do trabalho (êle o é, de modo direto, imediato), mas tôda a sociedade dêle se beneficia, ainda que indiretamente, de modo mediato.

Porém, ainda que assim não se queira entender, a realidade tendo demonstrado que a responsabilidade exclusiva do empresário está resultando em mau atendimento ao trabalhador acidentado, impõe-se, em defesa dêste, de sua dignidade de pessoa humana, da sua família e da própria sociedade, que à Previdência Social se integre, não só a parte de reparação dos acidentes, mas também, e. por conseqüência, a fiscalização da parte relativa à prevenção pròpriamente dita, no sentido de serem evitados os acidentes do trabalho.

\section{BIBLIOGRAFIA CONSULTADA}

Antokoletz, Daniel - "Derecho del Trabajo y Previsión Social", Editorial Guillermo Kraft Limitada, Buenos Aires, 2. a edição, Tomo II, pgs. 349 e seguintes. Botija, Eugenio Perez - "Curso de Derecho del Trabajo", Editorial Tecnos S/A, Madrid, 1948, pgs. 455 e seguintes, 493 e seguintes.

Cesarino Jr., Antonio Ferreira - "Direito Social Brasileiro", Livraria Freitas Bastos S/A, Rio de Janeiro, 1963, Vol. II, pgs. 401 e seguintes.

De La Cueva, Mario - "Derecho Mexicano del Trabajo", Editorial Porrua S/A, pgs. 3 e seguintes, 49 e seguintes, 181 e seguintes.

Deveali, Mario Levi - "Curso de Derecho Sindical y de La Previsión Social", Victor P. de Zavalia - Editor, Buenos Aires, 1954, pgs. 323 e seguintes.

Krotoschin, Ernesto - "Tratado Prático de Derecho del Trabajo", Roque Depalma Editor Buenos Aires, 1955, Vol. I, pgs. 325 e seguintes.

Artigos de "O Estado de São Paulo"

Quadro estatístico de acidentes do trabalho ocorridos em 1966, organizado pela Dele. gacia Regional do Trabalho no Paraná. 